\title{
Competition versus collusion: the impact of consumer inertia
}

Citation for published version (APA):

Bos, A. M., Peeters, R. J. A. P., \& Pot, E. A. (2012). Competition versus collusion: the impact of consumer inertia. METEOR, Maastricht University School of Business and Economics. METEOR Research Memorandum No. 046 https://doi.org/10.26481/umamet.2012046

Document status and date:

Published: 01/01/2012

DOI:

10.26481/umamet.2012046

Document Version:

Publisher's PDF, also known as Version of record

\section{Please check the document version of this publication:}

- A submitted manuscript is the version of the article upon submission and before peer-review. There can be important differences between the submitted version and the official published version of record.

People interested in the research are advised to contact the author for the final version of the publication, or visit the DOI to the publisher's website.

- The final author version and the galley proof are versions of the publication after peer review.

- The final published version features the final layout of the paper including the volume, issue and page numbers.

Link to publication

\footnotetext{
General rights rights.

- You may freely distribute the URL identifying the publication in the public portal. please follow below link for the End User Agreement:

www.umlib.nl/taverne-license

Take down policy

If you believe that this document breaches copyright please contact us at:

repository@maastrichtuniversity.nl

providing details and we will investigate your claim.
}

Copyright and moral rights for the publications made accessible in the public portal are retained by the authors and/or other copyright owners and it is a condition of accessing publications that users recognise and abide by the legal requirements associated with these

- Users may download and print one copy of any publication from the public portal for the purpose of private study or research.

- You may not further distribute the material or use it for any profit-making activity or commercial gain

If the publication is distributed under the terms of Article $25 \mathrm{fa}$ of the Dutch Copyright Act, indicated by the "Taverne" license above, 


\section{Maastricht University}

I wan Bos, Ronald Peeters, Erik Pot

Competition versus Collusion: The I mpact of Consumer I nertia

RM/ 12/046

(RM/ 10/024 -revised-)

\section{METEOR}

Maastricht University School of Business and Economics

Maastricht Research School of Economics

of Technology and Organization

\section{P.O. Box 616}

NL - 6200 MD Maastricht

The Netherlands 


\title{
Competition versus Collusion: The Impact of Consumer Inertia*
}

\author{
Iwan Bos ${ }^{\dagger} \quad$ Ronald Peeters ${ }^{\ddagger} \quad$ Erik Pot ${ }^{\S}$
}

August 29, 2012

\begin{abstract}
We consider a model of dynamic price competition to analyze the impact of consumer inertia on the ability of firms to sustain high prices. Three main consequences are identified: (i) maintaining high prices does not require punishment strategies when firms are sufficiently myopic, $(i i)$ if buyers are sufficiently inert, then high prices can be sustained for all discount factors, and (iii) the ability to maintain high prices may depend nonmonotonically on the level of the discount factor. These results provide a number of valuable insights with regard to competitive and collusive pricing behavior. For example, our findings suggest that measures aiming at lowering the degree of consumer inertia may in fact facilitate collusion in network industries.
\end{abstract}

Keywords: Collusion; Consumer Inertia; Dynamic Competition.

JEL Codes: C73; D43; L13; L41.

\footnotetext{
*The content of this paper has been presented at ACLE (Amsterdam, 2010), Tilburg University (Tilburg, 2010), NAKE (Utrecht, 2010), SING-6 (Palermo, 2010), the Netherlands Competition Authority (The Hague, 2011), University of Groningen (Groningen, 2011), IIOC (Boston, 2011), Erasmus University Rotterdam (Rotterdam, 2011). We thank the respective audiences for their helpful comments and suggestions. R. Peeters gratefully acknowledges financial support of the Netherlands Organization for Scientific Research (NWO).

${ }^{\dagger}$ Department of Organization \& Strategy, Maastricht University, P.O. Box 616, 6200 MD Maastricht, The Netherlands. Email: i.bos@maastrichtuniversity.nl.

${ }^{\ddagger}$ Department of Economics, Maastricht University, P.O. Box 616, 6200 MD Maastricht, The Netherlands. Email: r.peeters@maastrichtuniversity.nl. Corresponding author.

${ }^{\S}$ Department of Quantitative Economics, Maastricht University, P.O. Box 616, 6200 MD Maastricht, The Netherlands. Email: erikalexanderpot@gmail.com.
} 


\section{Introduction}

Standard theory of industrial collusion assumes that firms essentially face a repeated prisoner's dilemma when attempting to fix prices above competitive levels. Slightly undercutting the collusive price presumably leads to an immediate and substantial increase in sales and thereby profits. Following modern economic theory, firms can sustain high prices by ensuring that cheating does not go unpunished. There is an incentive to abide by the collusive agreement when short-run gains of cheating fall short of future losses, which typically requires a credible punishment strategy as well as a sufficiently high discount factor. ${ }^{1}$ The notion that colluding oligopolists are confronted with an intertemporal trade-off between short-term gains and future losses lies at the heart of most contributions to the theory of industrial collusion.

A critical assumption in these studies is that a seller can increase its sales instantly and significantly by shaving its price below the agreed level. While clearly there are instances in which consumers respond quickly to price changes, it is often more realistic to assume that they will not switch suppliers instantaneously. For example, in many industries, customers exhibit brand loyalty, switching costs or a lack of information on the price and quality of competing products. Also, buyers may have established long-term contracts with their suppliers. ${ }^{2}$ These types of consumer inertia directly affect the intertemporal trade-off that oligopolists face. Given that demand is viscous, undercutting the collusive price does not lead to a shortterm gain but a loss. This holds because individual demand is not immediately affected by the change in price and existing customers spend less on the product or service. At the same time, however, cutting price might lead to additional future profits as buyers may switch over time to a lower priced firm.

The notion that buyers may not respond instantly to a price cut generates a number of interesting questions. How does (the degree of) consumer inertia affect the ability of firms to sustain collusion? Under what industry conditions can we expect firms to set high prices? In this paper, we seek to shed some light on these and related issues. Towards that end, we develop and analyze a reduced form model of dynamic price competition between two firms. In any given period, customers are loyal to their supplier independent of the price it charges. ${ }^{3}$ Both firms therefore have some market power over their existing customers. Yet, buyers might switch suppliers in future periods when they observe a price difference. Consequently, in deciding whether or not to cut price, firms are given the following options. On the one hand, a seller may charge a high price and thereby exploit its current customer

\footnotetext{
${ }^{1}$ Friedman (1971) was among the first to show that collusion is sustainable in the context of an infinitely repeated game when firms are sufficiently patient.

${ }^{2}$ Klemperer (1995) provides many arguments for why buyers may not instantly respond to a price cut.

${ }^{3}$ An alternative interpretation is that consumers face substantial switching costs. See, for example, Farrell and Shapiro (1988) and Beggs and Klemperer (1992).
} 
base ('harvesting incentive'). Yet, by doing so, it faces the risk of losing customers in the future when its rival chooses to price low. Alternatively, a seller may charge a low price, thereby foregoing short-run profits, but with some probability increase its market share in the future ('investment incentive').

In deciding whether or not to deviate from the collusive price, there are at least three factors that play an important role. First, this decision will be driven by the amount of additional sales that can potentially be obtained by cutting price. This depends on the relation between consumer tastes and preferences and product attributes. For instance, if products are significantly differentiated, then a price cut will only attract a limited number of additional buyers. Second, the decision depends on the likelihood that customers will indeed switch suppliers. This is a dynamic factor, which includes loyalty and informational effects. For example, a customer who purchased from a particular seller may, ceteris paribus, be more inclined to buy from this seller in the future. That is, consumers might not always opt for the cheapest product even when the products are functionally identical. ${ }^{4}$ Third, sustainability of high prices depends on the value of expected additional sales. Indeed, like in the standard model of collusion, the rate that is used to discount future profits is an important determinant of strategic pricing behavior. The model studied in this paper incorporates all three factors.

Summarizing our main results, sustainability of high prices does not require punishment strategies when firms are sufficiently myopic. This result holds for all customer preferences and any degree of consumer inertia. Moreover, high prices can be sustained for all discount factors when demand is sufficiently viscous. Finally, we find that the ability to maintain high prices may depend non-monotonically on the level of the discount factor. That is to say, collusion may be sustainable for extreme values of the discount factor, but not when firms are moderately patient. For this to occur, it is required that the industry exhibits network externalities and that buyers are sufficiently inert.

These results provide a number of interesting insights with regard to strategic pricing behavior. For example, our analysis sheds some light on when we may expect competition and collusion to lead to similar market outcomes. ${ }^{5}$ This is valuable information in light of antitrust enforcement, particularly because economic methods of cartel detection typically aim to discriminate between competitive and collusive pricing behavior. ${ }^{6}$ Moreover, for a particular degree of consumer inertia, a credible and severe punishment strategy might be insufficient to sustain high prices in some types of industries. In this case, firms may try

\footnotetext{
${ }^{4}$ One way to think about this is that there is an informational advantage about the quality of the product when used before. As a consequence, a customer has to put some (costly) effort in finding out whether he could better switch or not. Likewise, customers may be slow to become aware of the most attractive brand due to a lack of (or a lag in) relevant information.

${ }^{5}$ This possibility is also suggested by Radner (2003).

${ }^{6}$ See Harrington (2008) for an overview and discussion of economic methods of cartel detection.
} 
to influence the level of inertia to create a situation in which high prices can be sustained. For instance, sellers may facilitate collusion by agreeing not to advertise in each others home markets.

To our knowledge, this paper is the first to analyze the impact of consumer inertia on the sustainability of collusion while taking account of various degrees of demand viscosity as well as different types of industry. ${ }^{7}$ The only other study we are aware of that considers collusion in the presence of demand inertia is Padilla (1995). In the context of an infinitely repeated duopoly game with homogeneous goods, this work reveals that (tacit) collusion may be difficult to sustain when consumer switching costs are substantial. Switching costs reduce the incentive to defect, but at the same time limit the impact of punishment strategies. The latter effect is shown to dominate the former when switching costs are sufficiently large. Our results suggest that this outcome is likely to depend on the type of industry under consideration. Specifically, we find that demand viscosity may make it difficult to sustain high prices in network industries, whereas it may facilitate collusion in traditional markets.

This paper proceeds as follows. In the next section, the model is introduced and described. Section 3 solves the model and provides a full characterization of high price equilibria. In Section 4, we discuss some implications of our main findings. All proofs are relegated to the Appendix.

\section{Model}

Our prime purpose is to explore the qualitative impact of consumer inertia on the ability of firms to sustain high prices. Towards that end, we study a stylized model in which two firms interact over a time horizon of possibly infinite length. The structure of the model is concisely depicted in Figure 1.

At each point in time, firms find themselves in one of three states: the competitive state (state 2) or an absorbing monopolistic state in which one of them has captured the entire market (state 1 and state 3 ). Starting in the competitive state, firms simultaneously and independently choose between two prices: a high (collusive) price $H$ or a low (competitive) price $L$. These price choices affect immediate profits as well as the state transition.

We assume that demand is viscous in that customers will not respond instantly to price changes. As a result, both firms can temporarily exploit their installed customer base. In competition, each firm's sales are given by the parameter $s \in(0,1)$. For ease of analysis, production costs are assumed to be absent. Consequently, depending on whether firms opted for $H$ or $L$, profits in the competitive state are respectively given by $s h$ or $s \ell$ (with $h>\ell>0$ ).

\footnotetext{
${ }^{7}$ Strategic pricing behavior in the presence of demand viscosity is also studied in Chen and Rosenthal (1996) and Radner (2003). However, these papers do not consider consumer inertia in relation to (tacit) collusion.
} 


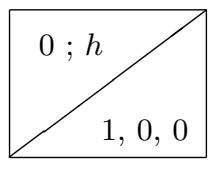

state 1

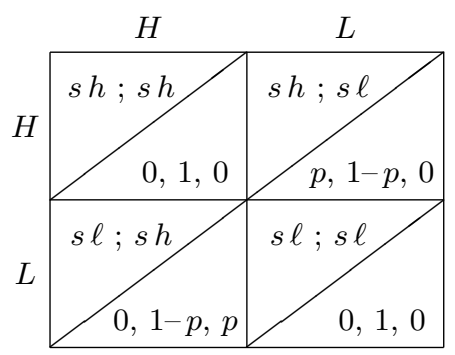

state 2

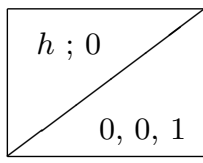

state 3

Figure 1: A duopolistic model of dynamic price competition with consumer inertia. In each cell, the north-west part shows respectively the profit of firm 1 (the row player) and firm 2 (the column player); the south-east part shows respectively the probability to transit to state 1 , state 2 and state 3 .

In a monopolistic state, the surviving firm is assumed to make a profit of $h$ in every period.

Despite the fact that the price choice does not affect current market shares, it can affect future sales and profits. If both firms choose the same action, then buyers remain loyal to their supplier and play resumes with probability 1 in the competitive state. When actions differ, buyers consider switching to the firm that set the low price. Specifically, if firm $i$ chooses $L$ and its rival chooses $H$, then play resumes with probability $p \in(0,1]$ in the absorbing state in which firm $i$ is a monopolist. With probability $1-p$, play resumes in the competitive state. Thus, cutting price leads to a decrease in short-term profits with certainty, but it also potentially increases future profits.

Both parameters $p$ and $s$ have a broader interpretation. The parameter $p$ is the probability that a price cut is successful in attracting additional sales. It therefore captures the degree of consumer inertia. For example, higher values of $p$ correspond to lower switching costs, more price awareness or less brand loyalty. The parameter $s$ represents the sales of a firm in competition relative to the sales it makes as a monopolist. When $s \geq \frac{1}{2}$, total sales in the competitive state (weakly) exceed the amount a monopolist can sell. This is characteristic for markets with differentiated goods or when products are complements. Thus, a larger $s$ can be interpreted as a higher level of differentiation or complementarity. By contrast, when $s<\frac{1}{2}$, total sales are higher when the market is served by one firm. This is typically the case when both firms sell incompatible network goods. A smaller $s$ then corresponds to a higher level of consumptive externalities. The parameters $p$ and $s$ thus allow us to take account of various degrees of demand viscosity and different types of markets.

Given a common discount factor $\delta \in[0,1)$, both firms maximize the expected present value of their profit stream. Notice that the presence of demand viscosity gives firms temporary market power, which fundamentally alters the intertemporal trade-off that oligopolists face in traditional models of industrial collusion. In a repeated prisoner's dilemma, firms compare short-term gains with future losses when deciding whether or not to cut price. If buyers are 
inert, then undercutting the collusive price is beneficial only when expected future profits outweigh short-term losses. Hence, firms have to decide whether to exploit their current customer base by charging a high price or to increase (or protect) their market share by setting a low price.

Before proceeding to the analysis, there are several assumptions of the model that warrant some discussion. First, there is only one competitive state and it is assumed that leaving this state is an irreversible act (i.e., there is no way back). Moreover, if buyers switch their supplier, then they do so in an orchestrated manner. As our objective is to study sustainability of collusion, one competitive state is sufficient. Of particular importance is that this state incorporates the intertemporal trade-off between exploiting the installed customer base and future profit opportunities. The way we have modeled consumer inertia in combination with the two absorbing monopolistic states captures this trade-off perfectly. Specifically, the assumption that the (expected) future gain is represented by a state that is both monopolistic and absorbing is anything but crucial. ${ }^{8}$ In fact, any potential reward would have sufficed.

Second, the action set is limited to two prices. In this respect, it is worth noting that Pot et al. (2011) studies a similar model. All results presented in that paper, as far as these are comparable, are consistent with Chen and Rosenthal (1996) and Radner (2003), both of which allow sellers to choose from a continuum of prices. In principle, we could extend the action space. However, this would make it significantly more complicated to provide a full characterization of high price (subgame perfect) equilibria, which is vital to studying collusive behavior.

\section{Results}

The framework introduced in the previous section is contained in the class of finite discounted stochastic games and we will use the conventional concepts and methods. The most general type of strategy a firm can formulate in this setting is a behavior strategy in which decisions are conditioned on state, time, full history of all visited states and all actions chosen. Given the initial state, a pair of behavior strategies constitutes a Nash equilibrium when neither of the firms can improve its (expected) profits by unilaterally adopting another behavior strategy. One particular type of behavior strategy that firms can employ is a stationary strategy in which decisions are independent of time and history and therefore conditioned on states only. A pair of stationary strategies that constitutes a Nash equilibrium is called a stationary equilibrium. The Nash equilibrium is subgame perfect when there does not exist any combination of state, time and history that allows a supplier to profitably defect.

\footnotetext{
${ }^{8}$ This is shown explicitly in Pot, Flesch, Peeters and Vermeulen (2011), where a similar model is studied.
} 
The next result establishes that high prices can be supported as a stationary subgame perfect equilibrium if and only if the discount factor is sufficiently low.

Proposition 1 (stationary behavior). High prices are sustainable as a stationary subgame perfect equilibrium if and only if

$$
\delta \leq \delta_{H} \equiv \frac{s(h-\ell)}{s(h-\ell)+p(1-s) h} .
$$

There exists no high price stationary subgame perfect equilibrium for sufficiently large discount factors as in that case the investment incentive dominates the harvesting incentive. Yet, high prices may still be sustainable as a subgame perfect equilibrium when firms adopt trigger strategies. A trigger strategy basically consists of three parts: (1) a specification of the collusive strategy, (2) a specification of a punishment strategy to be employed in the event of deviation from the collusive strategy, and (3) a specification of a strategy to be adopted when punished by the rival.

Clearly, firms choose high prices in the collusive phase. In case of defection, the most effective punishment is to price low. ${ }^{9}$ Notice that as the punishment strategy is stationary, the deviating firm has a stationary best response. However, whether the punished firm responds by setting a high or a low price depends on the level of the discount factor. Specifically, the punished firm optimally charges a low price when $\delta \geq \delta_{L} \equiv \frac{h-\ell}{h-(1-p) \ell}$ and a high price when $\delta<\delta_{L}$. The reason for this is that the immediate costs of fighting for survival exceed the future benefits of being in the competitive state when the discount factor is below the threshold $\delta_{L}$.

In sum, the trigger strategy for both firms is given by

$$
T= \begin{cases}H & \text { if } L \text { has not been chosen in any of the previous periods (collusion) } \\ L & \text { if the rival was the first to choose } L \text { (punishment) } \\ H & \text { if one was the first to choose } L \text { and } \delta<\delta_{L} \text { (response to punishment) } \\ L & \text { if one was the first to choose } L \text { and } \delta \geq \delta_{L} \text { (response to punishment). }\end{cases}
$$

Observe that the way in which the punishment affects the deviating firm's future profits differs for the two different ranges of the discount factor. For discount factors below $\delta_{L}$, there are no consequences for the future per-period profits as long as the market is in the competitive state. Yet, in every future period, there is a probability to be driven from the market. For discount factors above $\delta_{L}$, there is a relative loss in all future per-period profits, but none of the firms will ever obtain a monopoly position.

Next, we explore when the trigger strategy profile constitutes a subgame perfect equilibrium. For this to be the case, there are two requirements. First, the strategies employed in

\footnotetext{
${ }^{9}$ Indeed, charging a low price in each period following the period of defection is the most severe punishment strategy in our setting. Therefore, if high prices cannot be sustained by adopting this strategy, then collusion will not occur in any subgame perfect equilibrium.
} 
the punishment phase should constitute a (stationary) subgame perfect equilibrium. Second, deviation from the coordinated high price strategies should not be beneficial. The following proposition establishes that the first requirement is always satisfied.

Proposition 2 (punishment). Decisions in the punishment phase constitute a stationary subgame perfect equilibrium.

The conditions under which the second requirement is met depend on the value of the discount factor $\delta$ relative to the threshold $\delta_{L}$ as this determines the optimal strategy in the punishment phase.

Proposition 3 (sustainability). Suppose $\delta \geq \delta_{L}$. High prices are sustainable in subgame perfect equilibrium if and only if

$$
\delta \leq \delta_{L L} \equiv \frac{s(h-\ell)}{p(h-s \ell)} .
$$

Suppose $\delta_{H}<\delta<\delta_{L}$. High prices are sustainable in subgame perfect equilibrium if and only if

$$
\delta \notin\left(\delta_{L H}^{-}, \delta_{L H}^{+}\right)
$$

with

$$
\delta_{L H}^{-} \equiv \frac{2(1-p) s(h-\ell)+p(h-s \ell)-\sqrt{[2(1-p) s(h-\ell)+p(h-s \ell)]^{2}-4(1-p) s(h-\ell)[s(h-\ell)+p h]}}{2(1-p)[s(h-\ell)+p h]}
$$

and

$$
\delta_{L H}^{+} \equiv \frac{2(1-p) s(h-\ell)+p(h-s \ell)+\sqrt{[2(1-p) s(h-\ell)+p(h-s \ell)]^{2}-4(1-p) s(h-\ell)[s(h-\ell)+p h]}}{2(1-p)[s(h-\ell)+p h]} .
$$

The first part of Proposition 3 specifies the condition under which high prices are sustainable when in the punishment phase the punishing firm sets low prices and the deviating firm responds optimally by charging a low price. The condition states that high prices can be maintained as long as the discount factor does not exceed $\delta_{L L}$. Observe that the threshold $\delta_{L L}$ can give rise to two scenarios. If $\delta_{L L}$ is less than one, then high prices cannot be sustained for high discount factors (Scenario 2). Alternatively, if $\delta_{L L}$ exceeds one, then high prices are sustainable for sufficiently large discount factors (Scenario 1).

The second part of Proposition 3 specifies the condition under which high prices are sustainable when in the punishment phase the punishing firm sets low prices and the deviator responds optimally with a high price. The condition shows that, with the exception of an interval of intermediate values of the discount factor, high prices are sustainable in equilibrium. As before, two scenarios may arise, depending on whether the interval $\left(\delta_{L H}^{-}, \delta_{L H}^{+}\right)$has a nonempty intersection with the interval $\left(\delta_{H}, \delta_{L}\right)$ (Scenario b) or not (Scenario a). ${ }^{10}$

Combining Propositions 1, 2 and 3, the next result summarizes our findings so far.

\footnotetext{
${ }^{10}$ Note that non-emptiness of the interval $\left(\delta_{H}, \delta_{L}\right)$ requires $s<\frac{h}{h+\ell}$.
} 
Theorem 4. The effect of the discount factor on the sustainability of high prices as a (stationary) subgame perfect equilibrium takes one of the four forms as depicted in Figure 2.

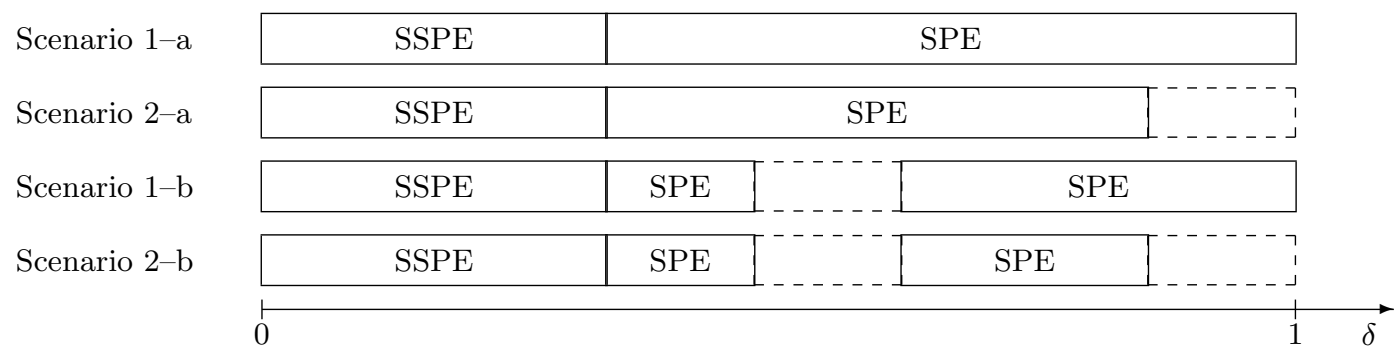

Figure 2: Sustainability of high prices by means of stationary strategies (SSPE) and trigger strategies (SPE) for different values of the discount factor. The values of the thresholds depend on the parameters $h, \ell, s$ and $p$ and are therefore not necessarily the same among the different scenarios.

Theorem 4 reveals that the presence of consumer inertia results in three main differences compared to an infinitely repeated prisoner's dilemma game. First, while it is well-known that in standard models of collusion high prices can be sustained in a subgame perfect equilibrium when the discount factor is sufficiently high, we here find a reversed effect. In all four scenarios, high prices are an equilibrium outcome when the discount factor is sufficiently low. The explanation for this is that firms have a short-term focus when the discount factor is low. If buyers are inert, then firms maximize their profits through exploiting their current customer base by setting a high price. Moreover, for very low discount factors, any change in future market shares is considered to be of little importance and setting a high price is a strictly dominant strategy.

A second difference caused by consumer inertia is the possibility that high prices are sustainable as a subgame perfect equilibrium for all values of the discount factor (Scenario 1-a). As Theorem 4 shows, for high discount factors this may require the use of trigger strategies. If firms know that defecting will evoke a punishment phase in which low prices will be set in all future periods, then their only incentive to deviate is the possibility to obtain a monopoly position. However, if demand is viscous or when only a few extra consumers can be gained by cutting price, then this potential "reward" may be insufficient to justify the immediate profit decrease that results from choosing a low rather than a high price. If this is the case, then high prices can be sustained in equilibrium independent of the value of the discount factor.

A third difference is that there may be a non-monotonicity in the sustainability of high prices (Scenario 1-b and 2-b). This striking result can occur for intermediate values of the discount factor. In this range, deviating from the trigger strategy is followed by a punishment phase in which the deviator responds optimally to the low price of its rival by setting a high 
price. In this case, the deviating firm foregoes part of its immediate profit in exchange for a chance to become a monopolist. In case monopoly is not attained, per-period profits of the deviator will be at collusive levels from the next period onwards, because choosing a high price is the optimal response to the punishment. Notice, however, that as the punishing firm sets a low price, the deviator faces the risk of losing its market share in every period. These rather subtle differences in the timing of different profit streams can give rise to the irregularity. Hypothetically, if we would let the discount factor increase from zero, we would find a threshold above which the expected profits of acquiring a monopoly position in period $t+1$ outweigh the immediate costs of cutting price in period $t$. At this point, high prices can no longer be supported as an equilibrium. Yet, if we would let the discount factor increase more, then the expected costs of losing market share from period $t+2$ onwards gains more weight. As a result, deviating becomes less attractive and high prices become sustainable again.

Which of the four scenarios applies depends on the value of the parameters $p$ and $s$, as the next result indicates.

Theorem 5. The relation between the parameters $p$ and $s$ and the scenarios of Theorem 4 is as depicted in Figure 3.

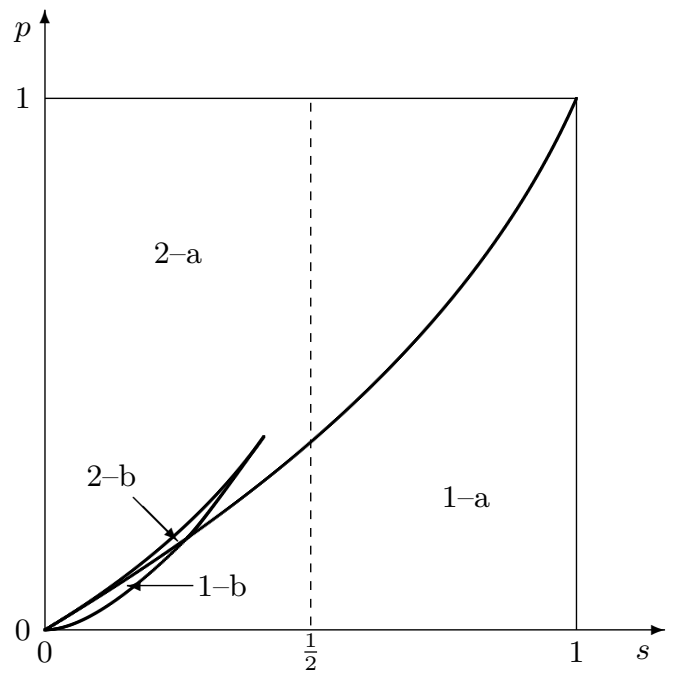

Figure 3: Relation between parameters and scenarios.

Scenarios 1-a and 1-b are characterized by high prices being sustainable for values of the discount factor arbitrarily close to one. Theorem 5 reveals that this situation arises for low values of $p$ and high values of $s$. In this case, chances of successful monopolization are low and the additional sales that can be obtained by cutting price are limited. As explained below Theorem 4, the reward of monopolization is not sufficient to justify the immediate profit 
decrease that results from choosing a low instead of a high price. This can be illustrated by looking at two extreme cases. If $p=0$, it is impossible to acquire a monopoly position and the high price strategy is (weakly) dominant for all values of the discount factor. If $s=1$, then the collusive profits are equal to the monopoly profits. Consequently, firms have no incentive to strive for a monopoly position and setting a high price is a dominant strategy for any level of the discount factor.

In Scenario 2-a and Scenario 2-b, high prices are not sustainable for discount factors sufficiently close to one. Theorem 5 reveals that this situation may arise for high values of $p$ and low values of $s$. In this case, the probability of successful monopolization is significant and firms can potentially increase their sales substantially by cutting price. Looking at the extreme case where $p=1$, undercutting the collusive price is guaranteed to be successful and firms that are sufficiently patient will surely aim to monopolize the market (or equivalently, avoid being monopolized). In the other extreme case where $s=0$, investment costs are zero and the punishment strategy will be completely ineffective. Therefore, both firms would price aggressively to gain market share (or equivalently, not to lose any).

Finally, the banana-shaped area in Figure 3 reveals that the non-monotonicity in the sustainability of high prices (Scenario 1-b and 2-b) can only occur for relatively low values of $s$ and $p$. In particular, such non-monotonicities are absent for values of $s$ above $\frac{1}{2}$.

Corollary 6 (traditional industries). Suppose $s \geq \frac{1}{2}$. If high prices can be sustained at a given discount factor, then these can also be sustained at any lower discount factor.

Hence, only when $s$ is sufficiently low (but certainly less than $\frac{1}{2}$ ), sustainability of high prices may depend non-monotonically on the level of the discount factor. Furthermore, it is required that $p$ is not too high, but not too low either.

Corollary 7 (network industries). Suppose $s<\frac{1}{2}$. It is possible that high prices cannot be sustained at a given discount factor, whereas these can be sustained for lower and higher values of the discount factor.

\section{Discussion}

A common assumption in the theory of industrial collusion is that undercutting the collusive price leads to an instant and substantial increase in sales and profits. In many industries, however, buyers are hesitant to switch suppliers in response to a price cut. This may for example be due to switching costs, contractual commitments and brand loyalty. In this paper, we have explored the impact of such consumer inertia on the ability of firms to sustain high prices. Contrary to predictions of the standard model of collusion, high prices are always sustainable when the value of expected future profits is sufficiently low. Moreover, there is a 
possibility that high prices can be maintained for all values of the discount factor. Finally, whether or not collusion is feasible may depend non-monotonically on the patience level of firms. If firms are only moderately patient, then high prices might not be sustainable when the industry exhibits network effects and demand is sufficiently viscous.

These results provide a number of interesting and important insights with regard to strategic firm behavior. First, our analysis reveals that high prices can be supported as a stationary subgame perfect equilibrium. Thus, setting high prices does not necessarily require an implicit or explicit coordination of actions. In particular, no triggers or threats are needed to reach the most profitable market outcome. High prices can therefore emerge naturally in competition and do not necessarily result from collusive practices. As such, this result is not new. For example, in markets with differentiated goods, firms typically have the power to raise prices without losing too many customers. Yet, a fundamental difference with our results is that the stationary high price equilibrium can occur in all four scenarios and therefore does not rely on the degree of consumer inertia and differentiation (type of market). Consequently, high prices in competition may not be driven only by a demand-side characteristic (e.g., consumer taste). In fact, we find that it is caused by a supply-side characteristic; the patience level of firms as reflected by the discount factor.

Moreover, when firms are sufficiently myopic, the stationary high price equilibrium is the unique equilibrium outcome. As the patience level of firms is typically unknown, this raises the question of how to distinguish between competitive and collusive pricing behavior. Arguably, low prices is the preferred market outcome from the perspective of consumers. Yet, in this situation, it seems difficult to effectively incentivize firms to no longer charge high prices. In particular, it is doubtful whether standard antitrust remedies can be effective in this case, because clearly no collusive conduct can be demonstrated when firms set high prices without coordinating their actions. There seems to be no obvious solution to this problem. Perhaps, regulating prices is currently the only available measure to improve consumer welfare in this particular situation.

A second main finding is that high price equilibria may exist for all values of the discount factor (Scenario 1-a). This occurs when buyers are sufficiently inert or when the number of customers that can be gained by cutting price is limited. Hence, the market situation and consumer characteristics might be such that firms always have a possibility to sustain high prices. This can potentially be remedied by lowering the degree of consumer inertia. Theorem 5 shows that, ceteris paribus, by increasing $p$ (the likelihood that a price reduction results in attracting more consumers), we may end up in Scenario 2-a; a state in which high prices cannot be sustained for high levels of the discount factor. Thus, our analysis indicates that it may be worthwhile to take measures that result in less demand viscosity. For instance, our findings provide some support for decisions that lead to more price transparency and 
short-term contracts. ${ }^{11}$ If such measures are successful and firms are sufficiently patient, then this may provide them with an incentive to charge low prices.

We furthermore find that, under certain conditions, high prices cannot be sustained for moderate values of the discount factor, while these would be sustainable for more extreme values of the discount factor. This can occur only when the industry exhibits network effects or when there is a lack of a common standard. The fact that the ability of firms to maintain high prices can depend non-monotonically on the level of the discount factor may have some important implications. For example, suppose that an economy-wide restriction on long-term contracts is introduced in order to reduce the level of consumer inertia. Although this can have a beneficial effect in some markets for reasons described above, it potentially helps firms to escape from Scenario b and bring them into Scenario a. Consequently, measures that aim to lower the degree of consumer inertia can have adverse effects and, in fact, facilitate collusion in network industries.

It is important to realize that the applicable scenarios are partly endogenous. That is to say, both the parameters $p$ and $s$ can to some extent be influenced by firms and therefore can potentially be used to facilitate collusion. For example, if firms are very patient and find themselves in Scenario 2-a, then they could try to enhance consumer inertia (e.g., take measures to increase switching costs). This may bring them into Scenario 1-a in which high prices can be supported as a subgame perfect equilibrium. Depending on the magnitude, measures increasing consumer inertia may even create a situation in which high prices become sustainable in stationary strategies in which case no coordination of actions is required to get the most profitable market outcome. Similarly, if firms find themselves in the "non-monotonic area" of Scenario b, then they can try to affect the degree of consumer inertia to end up in Scenario a in which the non-monotonicity is absent. Observe that, in this case, an increase as well as a decrease in the level of consumer inertia can have the desired effect. Hence, firms may implement apparently pro-competitive measures that reduce the level of consumer inertia, with the sole purpose to create a situation in which high prices can be sustained.

These considerations imply that there are distinct possibilities for firms to benefit from communication in markets where buyers are inert. Particularly, agreeing to influence demand inertia might be equally effective, but easier to arrange and less conspicuous than a price-fixing agreement. ${ }^{12}$ Trying to change the level of consumer inertia is potentially more effective than fixing prices directly as it alters the incentives of firms to set a high or a low price. This type of

\footnotetext{
${ }^{11}$ Note, however, that increasing price transparency may have adverse effects when it allows firms to better observe the transaction prices of their rivals. See Albaek, Mollgaard and Overgaard (1997) in which it is suggested that the publication of firm-specific transaction prices in Danish markets for concrete led to a significant increase in prices.

${ }^{12}$ See, for instance, Genesove and Mullin (2001) who describe how the Sugar Cartel in the U.S. (1927-1936) colluded on various business practices so as to facilitate price collusion.
} 
strategy can be especially beneficial in markets with network effects, because in those markets it is most rewarding to acquire a dominant market position by becoming the standard. As we show in Bos, Peeters and Pot (forthcoming), the presence of demand viscosity also provides an explanation for why firms may choose to explicitly agree on prices rather than tacitly coordinating their conduct. Firms that talk about prices act in breach of antitrust rules and typically risk a fine or even a prison sentence. These (expected) costs make short-term profits relatively more important and if demand is viscous, then these short-term gains are maximized by setting high prices. Thus, antitrust enforcement may effectively function as a commitment device. ${ }^{13}$ In sum, our findings suggest that it may be more fruitful for society to try to affect firms' incentives by changing levels of consumer inertia rather than to punish behavior caused by adverse incentives.

\footnotetext{
${ }^{13}$ McCutcheon (1997) also shows that antitrust enforcement may have adverse effects when it makes collusion costly, but not too costly, but for a different reason. This paper argues that the expected costs created by antitrust law enforcement may prevent renegotiations in case of defection. Hence, antitrust can help in making the punishment strategy credible, thereby facilitating collusion.
} 


\section{Appendix: Proofs}

Proof of Proposition 1. For the proof we make use of the well-known property that a firm always has a stationary best response against a rival adopting a stationary strategy. Given that the rival adopts the stationary high price strategy, the present value of the profits that results from responding with the stationary strategy that prescribes to select the high respectively the low price is given by:

$$
V_{H}=s h+\delta V_{H} \quad \text { and } \quad V_{L}=s \ell+\delta\left\{p \frac{h}{1-\delta}+(1-p) V_{L}\right\}
$$

High prices are sustainable as a stationary subgame perfect equilibrium if and only if the stationary high price strategy is a best response. This is the case when

$$
V_{H} \geq V_{L} \quad \Longleftrightarrow \quad \frac{s h}{1-\delta} \geq \frac{(1-\delta) s \ell+\delta p h}{(1-\delta)(1-\delta(1-p))} \quad \Longleftrightarrow \quad \delta \leq \frac{s(h-\ell)}{s(h-\ell)+p(1-s) h} .
$$

Proof of Proposition 2. Suppose that the rival adopts the stationary low price strategy. Responding with the stationary low price strategy is optimal if and only if

$$
\frac{s \ell}{1-\delta} \geq \frac{s h}{1-\delta(1-p)} \quad \Longleftrightarrow \quad \delta \geq \frac{h-\ell}{h-\ell+p \ell}
$$

Consequently, the optimal response is to adopt the stationary high price strategy when $\delta<$ $\frac{h-\ell}{h-\ell+p \ell}$.

Vice versa, the stationary low price strategy must be a best response to the strategy adopted by the firm that deviated (high prices for discount factors below $\delta_{L}$ and low prices for larger discount factors). For discount factors exceeding $\delta_{L}$, it follows by symmetry. For discount factors below $\delta_{L}$ it is implied by Proposition 1, because that result shows that for $\delta>\delta_{H}$ the stationary low price strategy is optimal when the rival adopts the stationary high price strategy.

Proof of Proposition 3. Suppose $\delta \geq \delta_{L}$ and the rival adheres to the trigger strategy. Then, the present value of adhering to the trigger strategy equals $\frac{s h}{1-\delta}$, while a deviation generates a present value of $s \ell+\delta\left\{p \frac{h}{1-\delta}+(1-p) \frac{s \ell}{1-\delta}\right\}$. It can be easily verified that deviating is not profitable if $\delta<\delta_{L L}$.

Suppose now that $\delta_{H}<\delta<\delta_{L}$ and the rival adheres to the trigger strategy. Then, the present value of adhering to the trigger strategy equals $\frac{s h}{1-\delta}$, while deviating to the low price generates a present value of $s \ell+\delta\left\{p \frac{h}{1-\delta}+(1-p) \frac{s h}{1-(1-p) \delta}\right\}$. It can be easily verified that deviating is not profitable if $\delta$ is such that

$$
(1-p)[s(h-\ell)+p h] \cdot \delta^{2}-[2(1-p) s(h-\ell)+p(h-s \ell)] \cdot \delta+s(h-\ell) \geq 0 .
$$

This quadratic inequality is satisfied when $\delta$ is smaller than $\delta_{L H}^{-}$or larger than $\delta_{L H}^{+}$. 
Proof of Theorem 4 and Theorem 5. We prove both theorems along the following lines. First, we provide the conditions that determine whether the model is in Scenario 1 or in Scenario 2. Next, the conditions that distinguish scenario a and $b$ are derived. Finally, we show - after illustrating the conditions graphically - that all combinations of conditions are compatible. More precisely, we show that, for each $h$ and $\ell$, there exist values of $p$ and $s$ such that the conditions are met.

Scenario 1 and 2. The only condition that needs to be satisfied for the model to be in Scenario 1 is $\delta_{L L}>1$; or, $p<\frac{s(h-\ell)}{h-s \ell}$. Otherwise, the model is in Scenario 2.

Scenario $\mathbf{a}$ and $\mathbf{b}$. There are three conditions that need to be satisfied for the model to be in Scenario b: (1) $\delta_{L H}^{-}, \delta_{L H}^{+} \in \mathbb{R} ;(2) \delta_{L H}^{-}<\delta_{L}$; and (3) $\delta_{L L}>\delta_{L}$.

Condition (1). Without the first condition the intersection of $\left(\delta_{L H}^{-}, \delta_{L H}^{+}\right)$with $\left(\delta_{H}, \delta_{L}\right)$ is guaranteed to be nonempty. This condition is satisfied if and only if $p \geq \frac{4 h s^{2}(h-\ell)}{4 h s^{2}(h-\ell)+(h-s \ell)^{2}}$.

Condition (2). It can be easily verified that, whenever the first condition is satisfied, $\delta_{L H}^{+} \geq$ $\delta_{L H}^{-}>\delta_{H}$. The second condition guarantees that the earlier intersection is nonempty, and hence there is a range of discount factors in $\left(\delta_{H}, \delta_{L}\right)$ for which high prices are not sustainable. This condition is satisfied if and only if

$$
\begin{gathered}
{[h-\ell+p \ell] \sqrt{[2(1-p) s(h-\ell)+p(h-s \ell)]^{2}-4(1-p) s(h-\ell)[s(h-\ell)+p h]}} \\
>p(h-s \ell)[h-\ell+p \ell]-2 p(1-p)(h-\ell)(h-s \ell) .
\end{gathered}
$$

This inequality is certainly satisfied when the right hand side is negative, i.e., $p<\frac{h-\ell}{2 h-\ell}$. Suppose next that the right hand side is positive. Then, with some effort, the inequality can be rearranged to $p(h-2 s \ell)>s(h-\ell)$.

Condition (3). The third condition warrants that there is range of discount factors just above $\delta_{L}$ for which high prices are sustainable by means of trigger strategies. By continuity of the present values it follows that this condition implies that there is also a range of discount factors just below $\delta_{L}$ for which high prices are sustainable. Hence, this condition implies $\delta_{L H}^{+}<\delta_{L}$. This condition is satisfied if and only if $p(h-2 s \ell)<s(h-\ell)$.

Notice that the second and third condition are incompatible when $p>\frac{h-\ell}{2 h-\ell}$. From this it can be concluded that Scenario b can only occur when $p<\frac{h-\ell}{2 h-\ell}$.

Graphical representation of conditions. Figure 4 plots the relevant curves. Curve $c .1$ plots precisely the parameter values separating Scenario 1 and 2: $p=\frac{s(h-\ell)}{h-s \ell}$. The other three curves - c.2, c.3 and $c .4$ - enclose Scenario b. First, curve $c .2$ plots the values of $p$ above which condition (1) is satisfied; that is, $p=\frac{4 h s^{2}(h-\ell)}{4 h s^{2}(h-\ell)+(h-s \ell)^{2}}$. Next, curve $c .3$ plots the values of $p$ below which condition (2) is satisfied, while enabling compatibility of condition (2) and (3): $p=\frac{h-\ell}{2 h-\ell}$. Finally, curve $c .4$ captures the condition $p(h-2 s \ell)<s(h-\ell)$. For $s \geq \frac{h}{2 \ell}$ this condition is satisfied for all values of $p$. For lower values of $s$ it requires $p<\frac{s(h-\ell)}{h-2 s \ell}$. Curve $c .4$ 


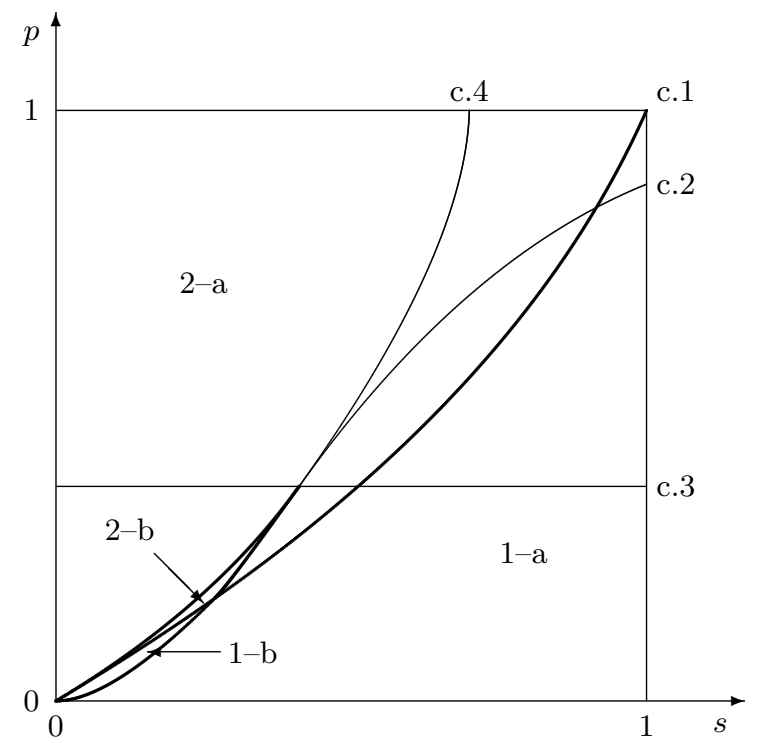

Figure 4: Relation between parameters and scenarios.

plots the values for which $p=\frac{s(h-\ell)}{h-2 s \ell}$. All values of $p$ and $s$ to the south-east of this curve, and only these values, are compatible with condition (3).

Non-emptiness of the areas. Suppose for the moment that $s<\frac{h}{2 \ell}$. Curve $c .2$ is below curve $c .4$ if and only if $(2 h+\ell)^{2} s^{2}-2 h(2 h+\ell) s+h^{2}>0$, which is satisfied for all $s$ except for $s=0$ and $s=\frac{h}{2 h+\ell}$. At the latter point the two curves are tangent to each other, and the corresponding value of $p$ at this point is $\frac{h-\ell}{2 h-\ell}$. Hence, both curves intersect curve $c .3$ at precisely this point. Notice that this is at a value of $s$ below $\frac{h}{2 \ell}$, which is in agreement with our supposition. This guarantees non-emptiness of Scenario b. Next, non-emptiness of the area 2 -b results from curve $c .1$ being below curve $c .4$ with exception of the origin. Finally, non-emptiness of the area $1-\mathrm{b}$ follows from the slope of curve $c .2$ being less than the slope of curve $c .1$ at the origin: $0<\frac{h-\ell}{h}$. 


\section{References}

[1] Albaek, S., P. Mollgaard and P.B. Overgaard (1997), "Government-Assisted Oligopoly Coordination? A Concrete Case," Journal of Industrial Economics, 45(4), 429-443;

[2] Beggs, A. and P. Klemperer (1992), "Multi-period Competition with Switching Costs," Econometrica, 60(3), 651-666;

[3] Bos, I., R. Peeters and E. Pot (forthcoming), "Do Antitrust Agencies Facilitate Meetings in Smoke-Filled Rooms?," Applied Economics Letters;

[4] Chen, Y. and R.W. Rosenthal (1996), "Dynamic Duopoly with Slowly Changing Customer Loyalties," International Journal of Industrial Organization, 14(3), 269-296;

[5] Farrell, J. and C. Shapiro (1988), "Dynamic Competition with Switching Costs," RAND Journal of Economics, 19(1), 123-137;

[6] Friedman, J.W. (1971), "A Non-cooperative Equilibrium for Supergames," Review of Economic Studies, 38(1), 1-12;

[7] Genesove, D. and W.P. Mullin (2001), "Rules, Communication and Collusion: Narrative Evidence from the Sugar Institute Case," American Economic Review, 91(3), 379-398;

[8] Harrington, J.E. (2008), "Detecting Cartels," in: Handbook in Antitrust Economics, Buccirossi, P., ed., MIT Press, Cambridge, MA;

[9] Klemperer, P. (1995), "Competition when Consumers have Switching Costs: An Overview with Applications to Industrial Organization, Macroeconomics and International Trade," Review of Economic Studies, 62(4), 515-539;

[10] McCutcheon, B. (1997), "Do Meetings in Smoke-Filled Rooms Facilitate Collusion?," Journal of Political Economy, 105(2), 330-350;

[11] Padilla, A.J. (1995), "Revisiting Dynamic Duopoly with Consumer Switching Costs," Journal of Economic Theory, 67(2), 520-530;

[12] Pot, E., J. Flesch, R. Peeters and D. Vermeulen (2011), "Dynamic Competition with Consumer Inertia," METEOR Research Memorandum, 11/016, Maastricht University;

[13] Radner, R. (2003), "Viscous Demand," Journal of Economic Theory, 112(2), 189-231. 